\title{
Meiosis in haploid rye: extensive synapsis and low chiasma frequency
}

\author{
J. L. SANTOS*, M. M. JIMÉNEZ \& M. DÍEZ \\ Department of Genetics, Faculty of Biology, Universidad Complutense de Madrid, 28040 Madrid, Spain
}

\begin{abstract}
Extensive synaptonemal complex formation was found at prophase I in whole mount spread preparations of a spontaneous haploid rye, Secale cereale, with values of up to 87.8 per cent of the chromosome complement synapsed. Pairing-partner switches were frequent, giving rise to multiple associations in which all or most of the chromosomes were involved. However, the distribution of synaptonemal complex stretches suggests that synapsis does not occur at random. The frequency of multivalents and the mean frequency of bonded arms at metaphase I were 0.03 and 0.39 , respectively. Associations between chromosome arms without heterochromatin were more frequent than between the remaining arms. The observation of recombinant chromosomes for telomeric C-bands at anaphase I indicates that metaphase I bonds are true chiasmata. The correspondence between the location of pairing initiation sites and chiasmata indicates that early synapsis could be confined to homologous regions.
\end{abstract}

Keywords: C-bands, haploid rye, metaphase I bonds, rye, Secale cereale, synapsis.

\section{Introduction}

Individuals with chromosome numbers corresponding to those of the gametes of their species are designated by the general term 'haploids'. An individual with the gametic chromosome number derived from a diploid species is called 'monoploid' or simply 'haploid', whereas the term 'polyhaploid' is used when it is produced from a polyploid species.

Haploids provide a good opportunity to study the influence of abnormalities of gene or genome doses in developmental, genetical and evolutionary phenomena. Furthermore, monoploids are particularly interesting for meiotic studies because each chromosome lacks its normal homologous partner and hence cannot undergo regular homologous synapsis and chiasma formation.

Observations on meiotic chromosome behaviour of haploids have mainly been restricted to metaphase I and later stages (for reviews, see Kimber \& Riley, 1963; Magoon \& Khanna, 1963; Sadasivaiah, 1974). A common feature of different monoploids is the presence of associations of two or more chromosomes in metaphase I cells. Whereas random bivalent formation has been suggested by Govindaswami \& Henderson (1965) and Manga \& Pantulu (1971) in rice and pearl millet, respectively, this does not seem to be

*Correspondence. the case in different monoploids of rye (Levan, 1942; Neijzing, 1982; de Jong et al., 1991).

Pachytene observations by light microscopy revealed occasional interchromosomal and intrachromosomal pairing in monoploids of rice (Chu, 1967), tomato (Ecochard et al., 1969), maize (Ting, 1966; Ford, 1970; Weber \& Alexander, 1972) and barley (Sadasivaiah \& Kasha, 1971, 1973). These findings were corroborated by studies based on threedimensional reconstruction of pachytene nuclei by electron microscopy that revealed the existence of synaptonemal complexes (SCs) in monoploids of tomato (Menzel \& Price, 1966), maize (Ting, 1973), petunias and snapdragons (Sen, 1970) and barley (Gillies, 1974). However, with this methodology only a limited number of nuclei can be analysed, which prevents a quantitative study of SC formation.

Surface spreading techniques for making whole mount preparations of SCs have recently been demonstrated in plants to be a powerful method for analysing early meiotic stages in a large number of nuclei. To date, the analysis of spread meiocytes has been carried out in a trihaploid wheat (Wang, 1988) and in a ditelosubstituted haploid of rye (de Jong et al., 1991). Our purpose is the application of a spreading technique to analyse the characteristics of the synaptic process in a spontaneous haploid of rye in order to establish a possible relationship between the pairing pattern and 
the frequency of the different chromosome associations observed at metaphase I.

\section{Materials and methods}

The haploid rye $(x=7)$ was found during a routine screening of Secale cereale plants from the inbred line T. This line was kindly supplied to us by Dr R. N. Jones (School of Agricultural Sciences, University College of Wales, Aberystwyth).

Single anthers of the emerging spikes were squashed in 2 per cent acetic orcein to locate the stages of meiosis. When prophase I was found, the two sister anthers of the same floret were prepared for SC isolation as described by Holm (1986), with minor modifications: 1 per cent 'Lipsol' detergent in the swelling medium and a fixative solution containing 4 per cent paraformaldehyde and 1.7 per cent sucrose in distilled water, adjusted to $\mathrm{pH} 8.9$ with borate buffer.

For metaphase I observations, the anthers were fixed in $1: 3$ acetic acid:ethanol and stored at $4{ }^{\circ} \mathrm{C}$. The fixed material was squashed and C-banded using the Giemsa staining procedure of Giráldez et al. (1979).

\section{Results}

\section{Prophase I}

Forty spread nuclei were examined by electron microscopy with meiotic stages ranging from leptotene to the onset of diplotene. Twelve nuclei were at diplotene, 10 were at leptotene since synapsis was absent and the remaining 18 showed SC stretches of different numbers and extents.

In the leptotene nuclei only the lengths of axial elements (AEs) could be measured. They ranged from $1467 \mu \mathrm{m}$ to $1215 \mu \mathrm{m}$ per nucleus with a mean of 1343 $\mu \mathrm{m}$. In some of them, and in others with less than 10 per cent of synapsis, a bouquet arrangement of telomeres was evident (Fig. 1). In nuclei showing synapsis the following variables were determined: the total nucleus complement length (TNC) (that is, the summed lengths of AEs and lateral elements (LEs)); the percentage of interchromosomal and intrachromosomal synapsis; the location of SC stretches throughout the chromosome; and the types of chromosome associations. All these data are listed in Table 1 and one of the analysed nuclei (number 13) is shown in Fig. 2.
Fig. 1 Whole mount silver-stained spread of a haploid Secale cereale nucleus at leptotene. The asterisk indicates the bouquet arrangement of telomeres. Bar represents $5 \mu \mathrm{m}$.

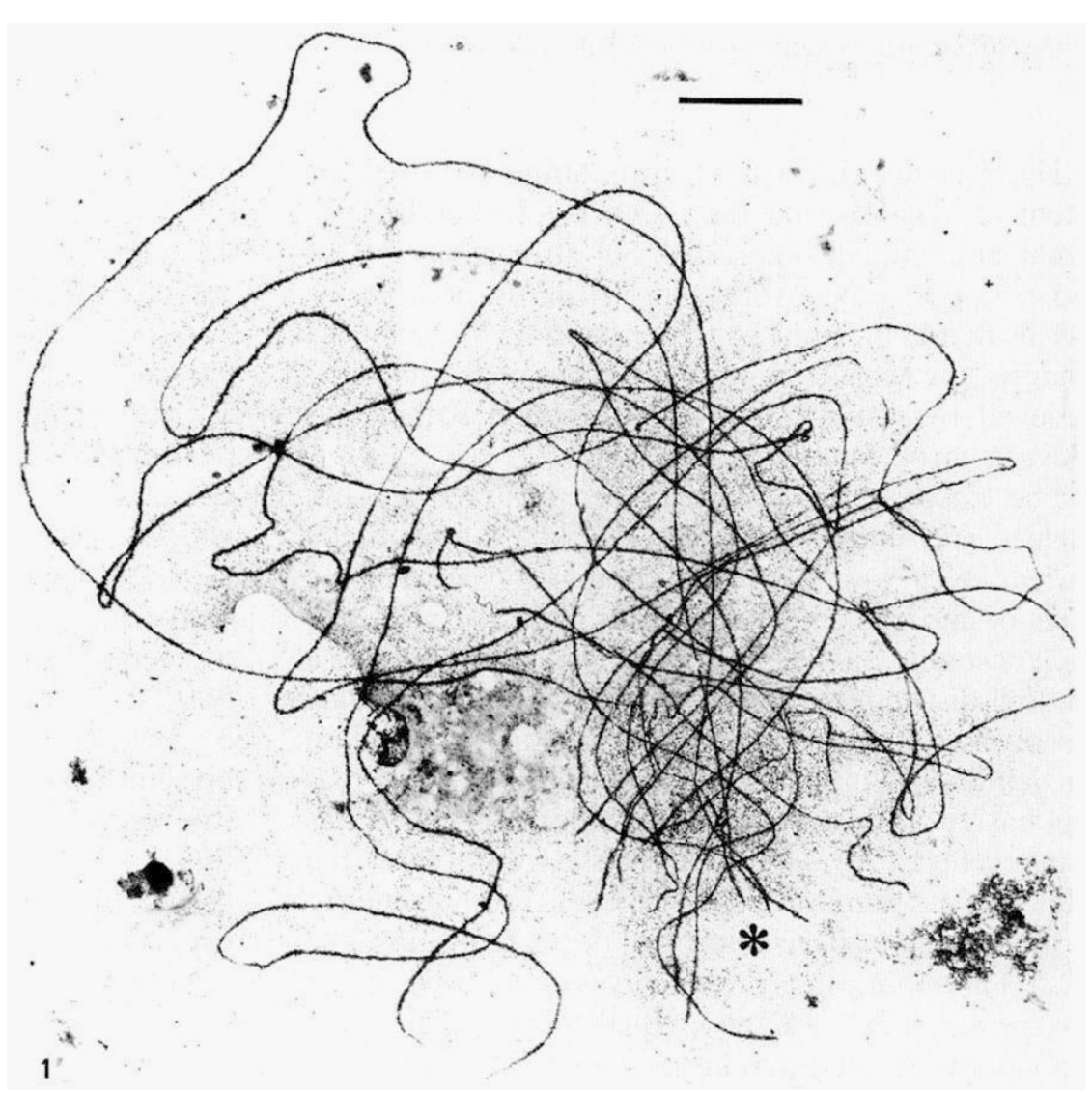


Table 1 Total nucleus complement lengths (TNC), degrees of synapsis, numbers and positions of SC stretches and types of chromosome associations in the nuclei of haploid rye Secale cereale

\begin{tabular}{|c|c|c|c|c|c|c|c|c|c|c|}
\hline \multirow[b]{2}{*}{ Nucleus } & \multirow[b]{2}{*}{$\mathrm{TNC}$} & \multirow{2}{*}{$\begin{array}{l}\text { Interchromosomal } \\
\text { synapsis }(\%)\end{array}$} & \multicolumn{3}{|c|}{$\begin{array}{l}\text { Interchromosomal } \\
\text { SC stretches }\end{array}$} & \multirow{2}{*}{$\begin{array}{l}\text { Intrachromosomal } \\
\text { synapsis }(\%)\end{array}$} & \multicolumn{2}{|c|}{$\begin{array}{l}\text { Intrachromo- } \\
\text { somal SC } \\
\text { stretches }\end{array}$} & \multirow{2}{*}{$\begin{array}{l}\text { Total SC } \\
\text { stretches }\end{array}$} & \multirow{2}{*}{$\begin{array}{l}\text { Chromosome } \\
\text { configuration }\end{array}$} \\
\hline & & & $\mathrm{D}$ & I & D-I & & $\mathrm{D}$ & I & & \\
\hline 1 & 1301 & 1.0 & 1 & - & - & - & - & - & 1 & 1II \\
\hline 2 & 1225 & 2.0 & 1 & - & - & - & - & - & 1 & 1II \\
\hline 3 & 1261 & 2.0 & 1 & - & - & - & - & - & 1 & 1II \\
\hline 4 & 1299 & 3.0 & 1 & - & - & - & - & - & 1 & 1II \\
\hline 5 & 1272 & 3.5 & 1 & - & - & - & - & - & 1 & III \\
\hline 6 & 1283 & 4.5 & 1 & - & - & 0.1 & 1 & - & 2 & 1II \\
\hline 7 & 1183 & 11.0 & 3 & 1 & - & 1.0 & 1 & - & 5 & $1 \mathrm{~V}$ \\
\hline 8 & 1062.5 & 12.8 & 3 & 2 & 1 & 2.6 & 2 & - & 8 & $1 \mathrm{~V}$ \\
\hline 9 & 1102.5 & 30.4 & 2 & 1 & - & 2.7 & 1 & - & 4 & $3 \mathrm{II}$ \\
\hline 10 & 1000 & 31.0 & 1 & 2 & 4 & 4.0 & - & 1 & 8 & 1VII \\
\hline 11 & 1080 & 37.0 & 1 & 3 & 1 & 3.0 & 1 & - & 6 & $1 \mathrm{IV}+1 \mathrm{II}$ \\
\hline 12 & 770 & 29.2 & 4 & 7 & 2 & 9.9 & 1 & 2 & 16 & 1VII \\
\hline 13 & 776 & 34.0 & 3 & 4 & 1 & 11.4 & 2 & 2 & 12 & $1 \mathrm{VI}^{*}$ \\
\hline 14 & 857.5 & 47.2 & 4 & 2 & - & 2.9 & 1 & - & 7 & 1VII \\
\hline 15 & 792 & 36.6 & 3 & 1 & 3 & 15.4 & 1 & 4 & 12 & $1 \mathrm{VI}^{*}$ \\
\hline 16 & 917 & 67.0 & 4 & 1 & 1 & 9.3 & 2 & - & 8 & $1 \mathrm{VII}$ \\
\hline 17 & 755 & 76.5 & 4 & 2 & 5 & 3.6 & - & 2 & 13 & $1 \mathrm{~V}+1 \mathrm{II}$ \\
\hline 18 & 785 & 57.7 & 4 & 1 & 1 & 30.1 & 4 & 3 & 13 & $1 \mathrm{~V}+1 \mathrm{II}$ \\
\hline
\end{tabular}

TNC, summed lengths of all lateral elements and axial cores; D, synaptonemal complex near or at telomeres; I, synaptonemal complex at interstitial region; D-I, synaptonemal complex between a distal or subdistal region of one chromosome and an interstitial region of another one.

*The remaining univalent is partially self-synapsed.

The existence of positive correlations between the extent of synapsis and the numbers of interchromosomal and intrachromosomal SC stretches $(r=0.64$ and $r=0.63$, respectively, with 16 d.f. in both cases) reveals that in the haploid there is a trend to maximum synapsis, the satisfaction of pairing requirements being achieved by simultaneous SC formation within and between chromosomes.

The extent of synapsis has been analysed at both nuclear and chromosomal levels. The study at the nuclear level was based on the comparison between the types of chromosome associations observed in the 18 nuclei listed in Table 1 and those expected assuming a random distribution of SC stretches along and among the seven rye chromosomes. The computer program for generating simulated random distributions of SCs was based on the simplified consideration of SCs as point events, with no difference in synapsis progression rates and the same probability for all chromosomes to be involved in intrachromosomal or interchromosomal SCs. Therefore, the probability of a single intrachromosomal SC $(1 / 7)$ was equal to one-sixth of the probability of an interchromosomal SC (6/7). The program was run 500 times for each given number of SCs $(1,2,3$ and so on). The expected frequencies of the different chromosome configurations are given in Table 2 and, although the number of nuclei analysed was low, it seems that SC distribution is not random. For instance:

1 we would expect to find three bivalents in only 3 per cent $(14 / 500)$ of the nuclei with four SCs, but this configuration appeared in the single nucleus observed with four SCs;

2 the two nuclei observed with 12 SCs showed one sexivalent plus one univalent whereas the expected frequency of this configuration was 18 per cent $(93 /$ 500 );

3 the two nuclei observed with 13 SCs showed one bivalent plus one quinquevalent, the expected frequency of this configuration being 0.4 per cent (2) $500)$.

The frequency of self-synapsis was also higher than expected. For instance, in nuclei with 12-13 SC segments the mean number of fold-backs was 4.5 , the expected frequency being 1.81 . 


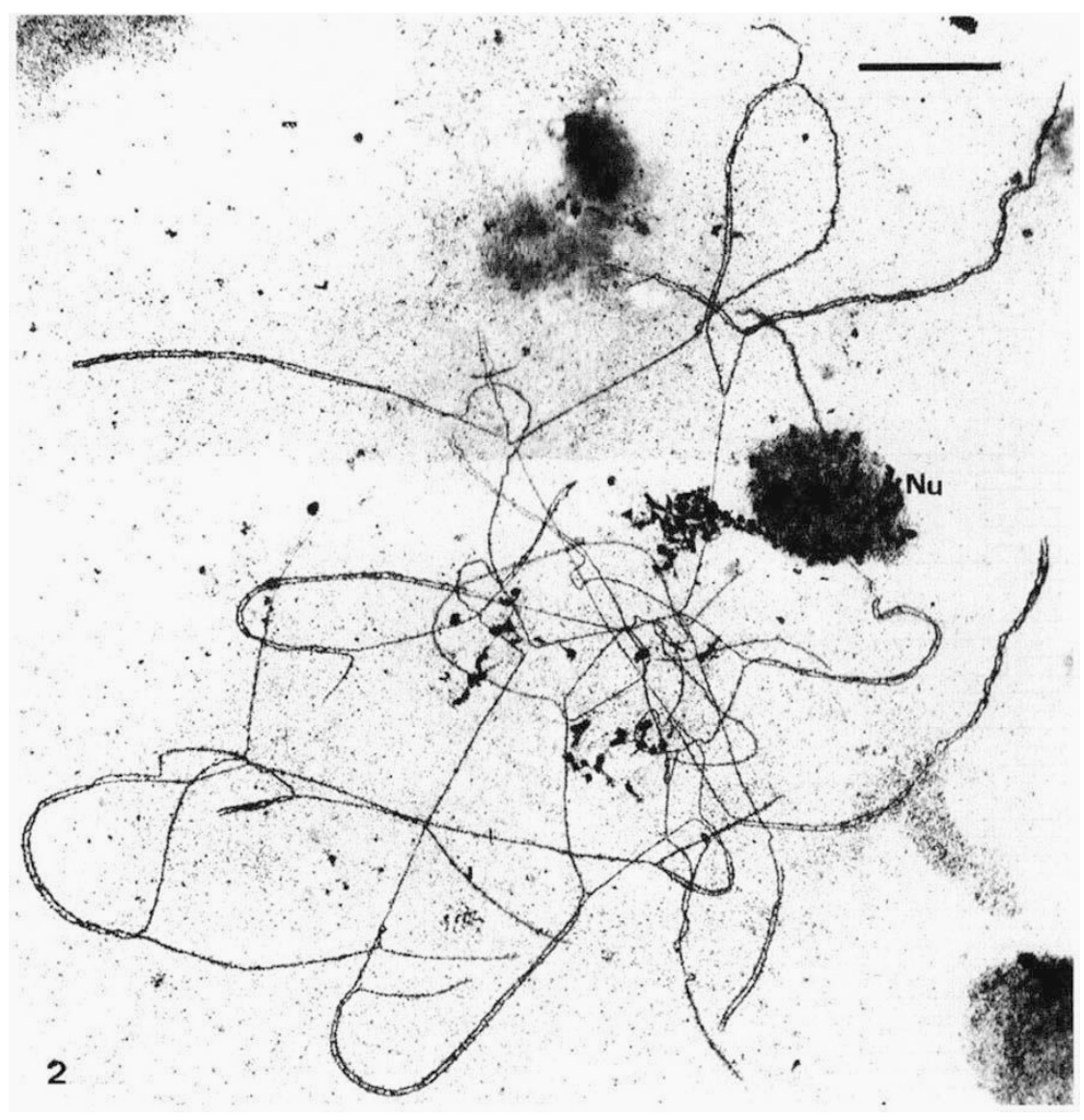

Fig. 2 Whole mount silver-stained spread of a nucleus (number 13 in Table 1) at mid-zygotene in which extensive synaptonemal complex formation is observed. $\mathrm{Nu}$, nucleolus. Bar represents $5 \mu \mathrm{m}$.

Table 2 Frequencies of the different pachytene chromosome associations in the haploid that should be expected assuming random distribution of SC stretches along and among the seven chromosomes of rye

\begin{tabular}{|c|c|c|c|c|c|c|c|c|c|c|c|c|c|c|}
\hline No. SC & $1 \mathrm{II}$ & $2 \mathrm{II}$ & $3 I I$ & $1 \mathrm{III}$ & $1 \mathrm{III}+1 \mathrm{II}$ & $1 I I I+2 I I$ & $2 \mathrm{III}$ & $1 \mathrm{IV}$ & $1 \mathrm{IV}+1 \mathrm{II}$ & $1 \mathrm{IV}+1 \mathrm{III}$ & $1 \mathrm{~V}$ & $1 \mathrm{~V}+1 \mathrm{II}$ & $1 \mathrm{VI}$ & $1 \mathrm{VII}$ \\
\hline 4 & 9 & 37 & 14 & 47 & 102 & 9 & 22 & 89 & 75 & & 96 & & & \\
\hline 5 & & 10 & 16 & 16 & 68 & 8 & 29 & 52 & 85 & 7 & 135 & 13 & 61 & \\
\hline 6 & & 4 & 2 & 3 & 19 & 12 & 19 & 32 & 63 & 27 & 130 & 36 & 128 & 25 \\
\hline 7 & & 1 & 1 & 1 & 7 & 5 & 23 & 14 & 43 & 16 & 89 & 46 & 182 & 72 \\
\hline 8 & & & & & 2 & 1 & 4 & 5 & 15 & 16 & 67 & 35 & 194 & 161 \\
\hline 12 & & & & & & & 1 & & 1 & & 9 & 8 & 93 & 388 \\
\hline 13 & & & & & & & & & & 3 & 6 & 2 & 75 & 414 \\
\hline
\end{tabular}

In all cases the number of nuclei was 500 .

The analysis of the extent of synapsis at the chromosomal level was not chromosome-specific since the spreading technique does not preserve the centromere structures; so neither the orientation of a given chromosome nor individual chromosomes could be identified. The positions of synapsed and unsynapsed regions were determined and their extents, expressed as percentages of the chromosome length in each nucleus, were plotted on the length of a standard rye chromosome displaying unknown orientation, so that in approximately 50 per cent of cases the chromosomes were in reverse orientation (Fig. 3). The mean numbers of SCs per chromosome in chromosomes showing $10-20,20-50$ and $50-80$ per cent of synapsis were $1.8,2.5$ and 3.1 , respectively. However, these values are likely to be underestimates because a long $\mathrm{SC}$ segment could be the consequence of the coalescence of two adjacent SCs. In fact, when two SC stretches are present in chromosomes synapsed in 10-20 per cent of their lengths they tend to be located in proximity, and, therefore, it appears that synapsis between two chromosomes promotes subsequent synapsis between other adjacent regions of the same chromosomes (Fig. 3). In nuclei with only one SC 


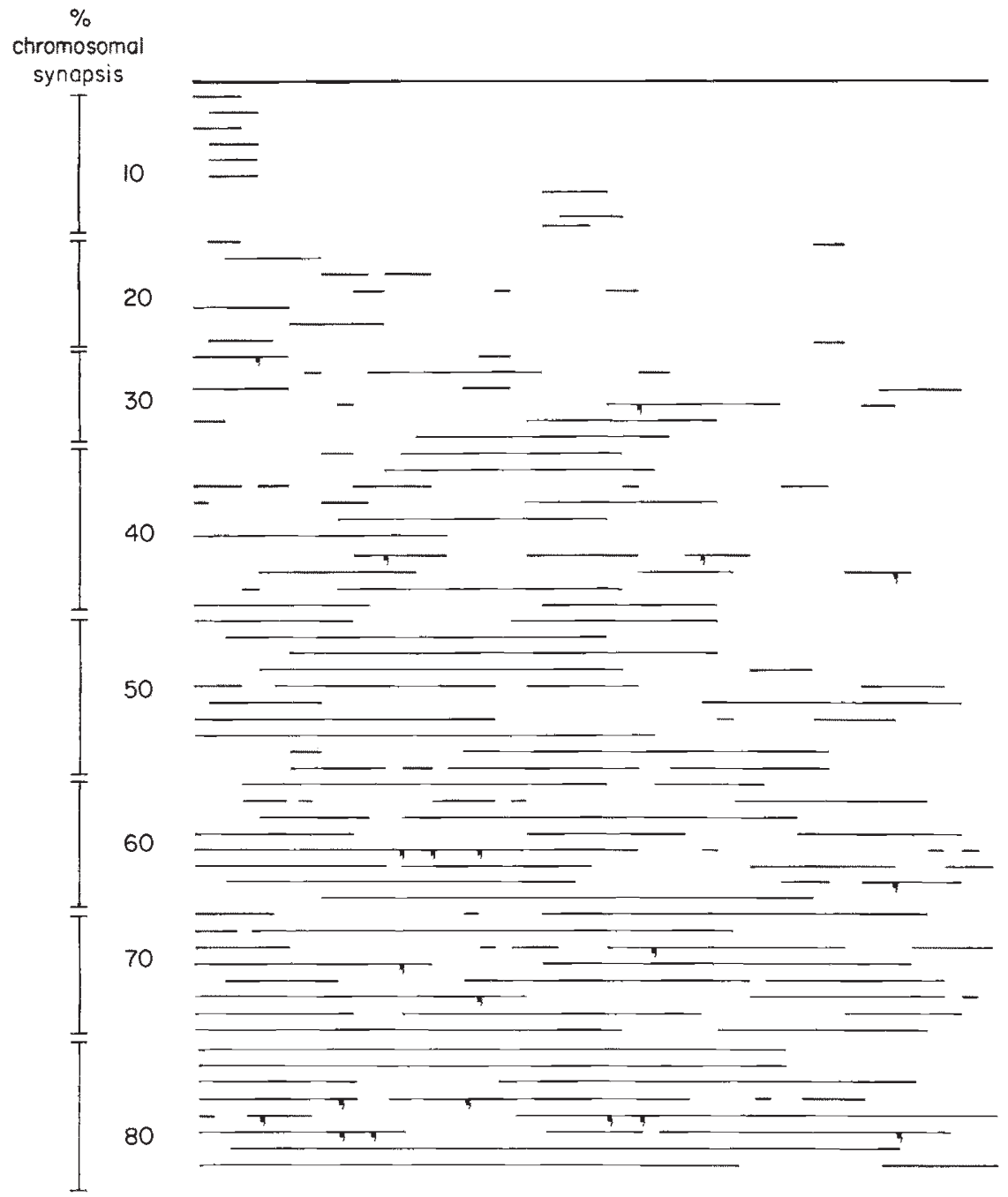

Fig. 3 The relative lengths and positions of paired regions (thin lines) in selected chromosomes from the 18 nuclei analysed plotted on the length of a standard chromosome (thick line at the top). Only 1-80 per cent of synapsed chromosomes are represented. Commas on the lines indicate pairing partner switches. segment it was usually located at or near telomeres and, to a lesser extent, in interstitial regions.

\section{Metaphase I}

Most rye chromosomes can be identified at mitosis according to their C-banding patterns and their arm length ratios (Giráldez et al., 1979). However, the identification at metaphase I presents more difficulties; in fact, the chromosomes of the haploid could only be divided into two groups: a group of four chromosomes with only one telomeric C-band and a group of three chromosomes with a C-band on both telomeres (Fig. 4a).

The total number of PMCs scored at metaphase I was 1100 and the different configurations observed are listed in Table 3. The maximum chromosome association was a quinquevalent (Fig. 4c). The random distribution of chromosome associations was tested in those cells with one open bivalent and five univalents by the method of Neijzing (1982). Theoretically, these chromosomes can lead to six different types of bivalent (Table 4). Assuming that each chromosome has the same probability of being bonded, the probability of a bivalent between two double-banded chromosomes (configuration A, Table 4) is 12/84; that of a bivalent of two single-banded chromosomes (configurations D, E and $F$ ) is 24/84; and that of a bivalent consisting of a single- and a double-banded chromosome (configurations B (Fig. 4b) and C) is 48/84. Within open bivalents of two chromosomes with one C-band each, the probabilities of bonds between unbanded arms (configuration D), between banded arms (configuration F) or between a banded and an unbanded arm (configuration $\mathrm{E}$ ) are $6 / 84,6 / 84$ and $12 / 84$, respectively. A bivalent formed by a single- and a double-banded chromosome has a probability of 24/84 that the bond is between two banded arms (configuration B) or between a banded and an unbanded arm (configuration C). There are significant differences between the observed and the expected values assuming random chromosome association (Table 4), and it is concluded, 
Fig. $4 \mathrm{C}$-banded metaphase I and anaphase I cells. (a) Metaphase I cell with seven univalents. (b) Metaphase I cell with a bond between a single- and a double-banded chromosome, configuration B (see text). (c) Metaphase I cell with a bivalent and a quinquevalent. (d) Anaphase I cell with two recombinant chromosomes (arrows). (e) Anaphase I cell with a dicentric bridge and acentric fragment involving banded and unbanded arms (arrow).

Table 3 Chromosome configurations at metaphase I of the haploid rye plants

\begin{tabular}{lc}
\hline Configuration & No. of PMCs \\
\hline $7 I$ & 752 \\
$6 I+1 I(O)$ & 8 \\
$5 I+1 I I(R)$ & 3 \\
$5 I+1 I(C)$ & 277 \\
$4 I+1 I I I(V)$ & 22 \\
$4 I+1 I I I(Y)$ & 6 \\
$3 I+2 I I(C)$ & 24 \\
$3 I+1 I V(N)$ & 1 \\
$2 I+1 I I I(V)+1 I I(C)$ & 5 \\
$2 I+1 I I(Y)+1 I I(C)$ & 1 \\
III $(C)+1 V(M)$ & 1 \\
\hline
\end{tabular}

$\mathrm{O}$, ring univalent; $\mathrm{R}$, ring bivalent; $\mathrm{C}$, open bivalent; $\mathrm{V}$, chain trivalent; Y, Y-trivalent; $N$, chain quadrivalent; $M$, chain quinquevalent.

therefore, that metaphase I bonds are nonrandomly distributed. Associations between arms without heterochromatin are more frequent than those between the remaining arms, but all of them are predominantly located at the distal ends of the chromosomes (Fig. $4 b, c)$.

\section{Anaphase I}

In haploids the term 'meta-anaphase' was coined to denote this period of the meiotic division because the absence of metaphase I plates and the distribution of univalents to poles make it difficult to distinguish both stages. Fortunately, in haploid rye the completion of metaphase I is indicated by the separation of univalent chromatids except at the centromere region.
Among 100 anaphase I cells analysed, 10 per cent showed a pair of recombinant chromosomes as a result of crossing-over between two arms with different telomeric C-banding patterns (Fig. 4d). In seven cells the exchange occurred in bivalents displaying configuration $\mathrm{C}$ (see Table 4) whereas in the remaining three cells the exchange occurred in E-type bivalents.

The frequency of a chromatid bridge plus an acentric fragment was 12 per cent, indicating either chiasma formation between homologous segments with reversed orientation, or U-type exchange between homologous segments with the same orientation. Only three recognizable combinations of arms were visualized at anaphase I, namely (i) those involving a singleand a double-banded chromosome $(3$ per cent, Fig. $4 \mathrm{e})$, (ii) two double-banded chromosomes ( 1 per cent) and (iii) two single-banded chromosomes ( 8 per cent). The sizes of the fragments were quite similar and large fragments were not observed.

Therefore, recombination was detected in 13 per cent of PMCs at anaphase I ( 10 per cent of segregating chromosomes plus 3 per cent which show 'recombinant' bridges and fragments), in good agreement with the frequency of bivalent configurations $\mathrm{C}$ and $\mathrm{E}$ observed at metaphase I ( 9 per cent, $\chi_{1}^{2}=1.73$, nonsignificant at 5 per cent level). Therefore, the mean of metaphase I bonds is a good estimate of the actual frequency of recombination. The location of chiasmata was always distal or subdistal.

\section{Discussion}

It is generally accepted that in the synaptic process there are two different phases (Moses et al., 1982; von Wettstein et al., 1984): early synapsis occurs strictly between homologous regions, but during mid to late 
Table 4 The six different types of open bivalents observed at metaphase I in haploid rye

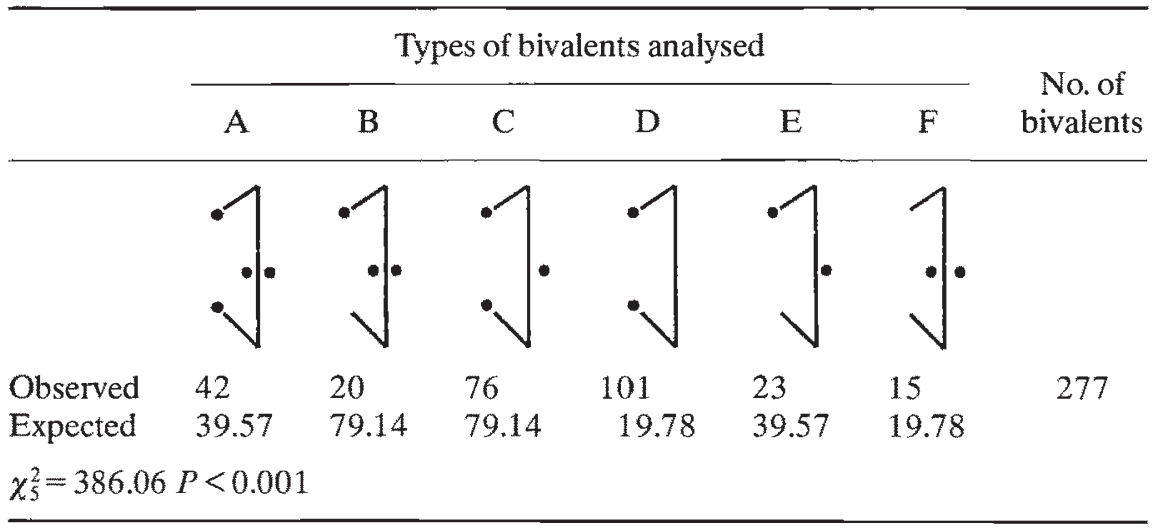

The numbers of each type in metaphase I cells with five univalents and one open bivalent are given, as well as the numbers expected assuming random chromosome associations.

pachytene nonhomologous synapsis can also take place. Miklos (1974) suggested that a saturation of pairing sites is necessary to permit a regular maturation of germ cells. In this context, the extensive synapsis observed in this haploid rye is considered to be nonhomologous and it takes place in order to satisfy pairing requirements. These results confirm previous reports on SC formation in other haploids (see Sadasivaiah (1974) for references). Completely reconstructed nuclei of barley (Gillies, 1974) and Physarum (Lie \& Laane, 1982) revealed up to 60 and 28 per cent, respectively, of the haploid complement synapsed whereas in surface spread nuclei of rye (de Jong et al., 1991; this work) and yeast (Loidl et al., 1991) the amount of synapsis was even higher.

Gillies (1974) interpreted the extent and nature of the SC formation in haploid barley as evidence that synapsis occurred at random. However, in higher plants, some homology can also reflect duplications and dispersed sequences within the haploid genome (Weber \& Alexander, 1972; Crane et al., 1982) or ancestral polyploidy (Armstrong \& Keller, 1981). In rye, there is evidence for the existence of both duplicate genes located in nonhomologous chromosomes (Rao \& Rao, 1980) and families of repetitive DNA sequences associated with heterochromatin (Bedbrook et al., 1980; Appels et al., 1981, 1986). Likewise, widely dispersed repetitive sequences or sequences in short tandem arrays unrelated to cytological or genetical features have also been isolated (Appels et al., 1986; McIntyre et al., 1990; Guidet et al., 1991). In addition, the SC distribution observed in this haploid rye suggests that synapsis does not occur at random. However, in spite of the extensive synapsis the mean number of bound arms per cell at metaphase I was only
0.38 . This value can be considered to be a good estimate of the actual chiasma frequency (see Results), although crossovers were only cytologically detected when they occurred between chromosome arms with different C-banding patterns (Fig. 4d). Chiasmata were located at or near telomeric regions and their distribution resembled that displayed by SC stretches when the pairing process starts (Fig. 3). Therefore, it is feasible that in haploid rye early synapsis is exclusively confined to homologous regions and that these sequence homologies are either more represented or more effective for crossing-over in those chromosomes without heterochromatin, since their involvement in metaphase I associations is higher than that of those arms with distal C-bands. This nonrandom involvement of chromosome arms in chiasma formation is in agreement with previous observations (Neijzing, 1982; de Jong et al., 1991).

The low frequency of bonded arms observed at metaphase I was also accompanied by a drastic reduction in multivalents, which were very frequent at prophase I (compare Tables 1 and 3). Although the number of prophase I nuclei analysed was low, a clear trend of multivalent elimination during synapsis progression does not seem to occur, so the reduction of multivalents from mid to late zygotene to metaphase I must reflect the restriction of chiasmata to homologously paired axial segments.

$\mathrm{SC}$ formation after the arrangement of telomeres in a bouquet disposition and the morphological SC features are similar in haploid and diploid rye. However, the range of the total nucleus complement length of the haploid (from $1343 \mu \mathrm{m}$ at leptotene to $755 \mu \mathrm{m}$ in one nucleus with 80.1 per cent of the complement synapsed) was higher than other values reported in 
diploid rye (Gillies, 1985; Benavente \& Santos, 1993). A similar situation was reported in haploid yeast by Loidl et al. (1991) although it was not observed in a ditelo-substituted haploid of rye (de Jong et al., 1991). Therefore if haploidy is accompanied by a different condensation behaviour at meiotic prophase, it might be a genotype-dependent phenomenon.

\section{Acknowledgements}

This paper was supported by a grant (PB 92-0182) awarded by the Comision Interministerial de Ciencia y Tecnoloía (Spain). José Barrios, Agustín Fernández and the staff of the Complutense University Electron Microscope Unit, especially Dr Carlos Barba, provided valuable assistance.

\section{References}

ARMSTrong, K. C. AND KEller, w. A. 1981. Chromosome pairing in haploids of Brassica campestris. Theor. Appl. Genet., 59, 44-52.

APPELS, R., DENNIS, E. S., SMYTH, D. R. AND PEACOCK, W. J. 1981. Two repeated DNA sequences from the heterochromatic regions of rye (Secale cereale) chromosomes. Chromosoma, 84, 265-277.

APPELS, R., MORAN, L. B. AND GUSTAFSON, J. P. 1986. Rye heterochromatin. I. Studies on clusters of the major repeating sequence and the identification of a new dispersed repetitive sequence element. Can. J. Genet. Cytol., 28, 645-657.

BEDBROOK, J. R., JONES, J., O'DELL, M., THOMPSON, R. D. AND FLAVELL, R. D. 1980. Molecular characterisation of telomeric heterochromatin in Secale species. Cell, 19, 545-560.

BENAVENTE, E. AND SANTOS, J. L. 1993. Meiotic behaviour of rye heterozygous for ditelocentric substitutions. Cytogenet. Cell. Genet., 62, 5-10.

CHU, Y. 1967. Pachytene analysis and observations of chromosome associations in haploid rice. Cytologia, 32, 87-95.

CRANE, C. F., BEVERSDORF, W. D. AND BINGNAM, E. T. 1982. Chromosome pairing and associations at meiosis in haploid soybean (Glycine max). Can. J. Genet. Cytol., 24, 293-300.

DE JONG, J. H., HAVEKES, F, ROCA, A. AND NARANJO, T. 1991. Synapsis and chiasma formation in a ditelo-substituted haploid of rye. Genome, 34, 109-120.

ECOCHARD, R., RAMANNA, M. S. AND DE NETTANCOURT, D. 1969. Detection and cytological analysis of tomato haploids. Genetica, 40, 181-190.

FORD, L. 1970. Chromosome association in Zea mays monoploids. The Nucleus, 13, 99-105.

GILLIES, C. B. 1974. The nature and extent of synaptonemal complex formation in haploid barley. Chromosoma, 48, 441-453.

GILLIES, C. B. 1985. An electron microscopic study of synaptonemal complex formation at zygotene in rye. Chromosoma, 92, 165-175.
girÁldez, R., CERMEÑo, M. C. AND orellana, J. 1979. Comparison of $\mathrm{C}$-banding pattern in the chromosomes of inbred lines and open pollinated varieties of rye. Z. PflZücht., 83, 40-48.

GOVINDASWAMI, S. AND HENDERSON, M. T. 1965. Cytological studies in haploid rice (Oryza sativa L.). Oryza (Cuttak), 2, 11-23.

GUIDET, F., ROGOWSKY, P., TAYLOR, C., SONG, W. AND LANGRIDGE, P. 1991. Cloning and characterisation of a new specific repeated sequence. Genome, 34, 81-87.

Holm, P. в. 1986. Chromosome pairing and chiasma formation in allohexaploid wheat, Triticum aestivum, analysed by spreading of meiotic nuclei. Carlsberg Res. Comm., 51, 239-294.

KIMBER, G. AND RILEY, R. 1963. Haploid angiosperms. Bot. Rev., 29, 490-531.

LEVAN, A. 1942. Studies on the meiotic mechanism of haploid rye. Hereditas, 28, 177-211.

LIE, T. AND LAANE, M. M. 1982. Reconstruction analysis of synaptonemal complexes in haploid and diploid pachytene nuclei of Physarum polycephalum (Myxomycetes). Hereditas, 96, 119-140.

LOIDL, J., NAIRZ, N. AND KLEIN, F. 1991. Meiotic chromosome synapsis in a haploid yeast, Chromosoma, 100, 221-228.

McINTYRE, C. L., PEREIRA, S., MORAN, L. B. AND APPELS, R. 1990. New Secale cereale (rye) DNA derivatives for the detection of rye chromosome segments in wheat. Genome, 33, 635-640.

MAgoon, M. L. AND Khanna, K. R. 1963. Haploids. Caryologia, 16, 191-234.

MANGA, v. AND PANTULU, J. v. 1971. The meiotic behaviour of a haploid pearl millet. Genetica, 42, 319-328.

MENZEL, M. Y. AND PRICE, J. M. 1966. Fine structure of synapsed chromosomes in $\mathbf{F}_{1}$ Lycopersicon esculentum-Solanum lycopersicoides and its parents. Am. J. Bot., 53, 1079-1086.

MIKLOS, G. L. C. 1974. Sex chromosome pairing and male fertility. Cytogenet. Cell. Genet., 13, 558-577.

MOSES, M. J., POORMAN, P. A., RODERICK, T. H. AND DAVISSON, M. T. 1982. Synaptonemal complex analysis of mouse chromosomal arrangements. IV. Synapsis and synaptic adjustment in two paracentric inversions. Chromosoma, 84, 457-474.

NEIJZING, M. G. 1982. Chiasma formation in duplicated segments of the haploid rye genome. Chromosoma, $\mathbf{8 5}$, 287-298.

RAO, I. N. AND RAO, M. V. P. 1980 . Evidence of duplicate genes coding for 6-phosphogluconate dehydrogenase in rye. Genet. Res., 35, 309-312.

SADASIVAIAH, R. s. 1974. Haploids in genetic and cytological research. In: Kasha, K. J. (ed.) Haploids in Higher Plants. Proceedings of the First International Symposium, pp. 355-386. University of Guelph, Guelph, Ontario.

SADASIVAIAH, R, S. AND KASHA, K. J. 1971. Meiosis in haploid barley. An interpretation of non-homologous chromosome associations. Chromosoma, 35, 247-263.

SADASIVAIAH, R. S. AND KASHA, K. J. 1973. Non-homologous associations of haploid barley chromosomes in the cytoplasm of Hordeum bulbosum L. Can. J. Genet. Cytol., 15, 45-52. 
SEN, S. K. 1970. Synaptonemal complexes in haploid Petunia and Antirrhinum sp. Naturwissenschaften, 57, 550.

TING, Y. C. 1966. Duplications and meiotic behaviour of the chromosomes in haploid maize (Zea mays L.). Cytologia, 31, 324-329.

TING, Y. C. 1973. Synaptonemal complex and crossing over in haploid maize. Chromosomes Today, 4, 161-167.

WANG, X. 1988. Chromosome pairing analysis in haploid wheat by spreading of meiotic nuclei. Carlsberg Res. Comm., 53, 135-166.

WEBER, D. F. AND ALEXANDER, D. E. 1972. Redundant segments in Zea mays detected by translocations of monoploid origin. Chromosoma, 39, 27-42.

VON WETTSTEIN, D., RASMUSSEN, S. W. AND HOLM, P. B. 1984. The synaptonemal complex in genetic segregation. Ann. Rev. Genet., 18, 331-413. 